\title{
Architecture of Micro Energy Harvesting Using Hybrid Input of RF, Thermal and Vibration for Semi- Active RFID Tag
}

\author{
Tengku Norliza Tengku Mohamad ${ }^{1,2, a}$, Jahariah Sampe $^{1, \mathrm{~b}}$, and Dilla Duryha Berhanuddin ${ }^{1}$ \\ 1 Institute of Microengineering and Nanoelectronic (IMEN), Universiti Kebangsaan Malaysia (UKM), \\ 43600 Bangi, Selangor, Malaysia \\ 2 Department of Electrical and Electronic Engineering, Faculty of Engineering, Universiti Pertahanan \\ Nasional Malaysia, Kem Sungai Besi, 57000, Kuala Lumpur, Malaysia \\ E-mail: anorli@upnm.edu.my, bjahariah@ukm.edu.my (Corresponding authors)
}

\begin{abstract}
This research work presents a novel architecture of Hybrid Input Energy Harvester (HIEH) system for semi-active Radio Frequency Identification (RFID) tags. The proposed architecture consists of three input sources of energy which are radio frequency signal, thermal and vibration. The main purpose is to solve the semi-active RFID tags limited lifespan issues due to the need for batteries to power their circuitries. The focus will be on the rectifiers and DC-DC converter circuits with an ultra-low power design to ensure low power consumption in the system. The design architecture will be modelled and simulated using PSpice software, Verilog coding using Mentor Graphics and real-time verification using field-programmable gate array board before being implemented in a $0.13 \mu \mathrm{m}$ CMOS technology. Our expectations of the results from this architecture are it can deliver $3.3 \mathrm{~V}$ of output voltage, $6.5 \mathrm{~mW}$ of output power and $90 \%$ of efficiency when all input sources are simultaneously harvested. The contribution of this work is it able to extend the lifetime of semi-active tag by supplying electrical energy continuously to the device. Thus, this will indirectly reduce the energy limitation problem, eliminate the dependency on batteries and make it possible to achieve a batteryless device.
\end{abstract}

Keywords: Hybrid input energy harvester, RF signal, thermal, vibration, rectifiers and DC-DC converter, semi-active RFID tag.

ENGINEERING JOURNAL Volume 21 Issue 2

Received 3 April 2016

Accepted 31 August 2016

Published 31 March 2017

Online at http://www.engj.org/

DOI:10.4186/ej.2017.21.2.183 


\section{Introduction}

Over the decades, Radio Frequency Identification (RFID) technology has become a popular system and has attracted a lot of attention in the industry and military applications. Its wireless functions as automatic identification and data collection solution have been widely used in numerous areas such as supply chain management, access control, logistic, asset visibility, structural and environmental monitoring, sensor networks, etc. Among the various applications of RFID, Ultra High Frequency (UHF) RFID has a better throughput and performance with its small antenna sizes, higher data rates and longer reading distance. Operating frequency range for UHF is between $860-960 \mathrm{MHz}$.

A military supply chain management is one of the biggest systems that implements and utilizes the RFID technology. The use of RFID makes it possible to provide effective inventory and asset management, monitor and track the use, movement and placement of the weapons and munitions, and theft prevention. Although UHF RFID tags technology has been studied for several decades, only recently researchers are focusing on semi-active tags. Until now, the design of the tag is still being developed and only a few reports are being published by researchers especially the use of energy harvesting as an external power source for the semi-active tags. The advantages of semi-active tags are they have a longer communication range and longer battery life than passive tags and active tags, respectively [1]. Moreover, their robustness, higher functionality and capability of performing scheduled tasks makes them suitable to be used for troop readiness and safety [2].

The major drawback of semi-active tags is their limited lifespan issues due to the need for batteries to power up the tag circuitry. Once the batteries died, the tags cannot be used and the information stored in the memory of the tag chip could not be read. Presently, a lifespan of semi-active RFID tag is two (2) to seven (7) years but this depends on their applications. Frequent use of the tags to read and write will make the batteries life become shorter [3]. Consequently, ongoing maintenance is needed as the batteries have to be replaced. The details strength and weaknesses of each RFID type are shown in Table 1.

Table 1. Comparison of strengths and weaknesses of each RFID type.

\begin{tabular}{|c|c|c|}
\hline RFID type & Strengths & Weaknesses \\
\hline Passive Tag & $\begin{array}{ll}\text { - } & \text { No internal power source (energy } \\
\text { transferred via RF signal) } \\
\text { - } & \text { Longer lifetime (> } 20 \text { years) } \\
\text { - } & \text { Smaller tag size and mechanically } \\
& \text { flexible, less expensive } \\
\text { - } & \text { Do not require any maintenance }\end{array}$ & $\begin{array}{l}\text { - Short read/write range }(4-5 \mathrm{~m}) \\
\text { - No sensor support } \\
\text { - } \quad \text { Require very strong RF signal from } \\
\text { reader to power the tag } \\
\text { - Small read/write data storage }\end{array}$ \\
\hline $\begin{array}{l}\text { Semi-passive/ } \\
\text { Semi-active Tag }\end{array}$ & $\begin{array}{ll}\text { - } & \text { Less expensive than active tag } \\
\text { - } & \text { Long read/write range }(>100 \mathrm{~m}) \\
\text { - } & \text { Has sensors } \\
\text { - Need very low RF signal strength } \\
\text { from reader }\end{array}$ & $\begin{array}{l}\text { - Use internal power source (battery) } \\
\text { - Limited battery lifetime (up to } 7 \text { years) } \\
\text { - Increase maintenance and cost of } \\
\text { operation due to batteries replacement } \\
\text { especially when it involves a large } \\
\text { number of tags. } \\
\text { - Increase environmental pollution when } \\
\text { disposing of the old batteries }\end{array}$ \\
\hline Active Tag & $\begin{array}{ll}\text { - } & \text { Long read range }(>100 \mathrm{~m}) \\
\text { - } & \text { Has sensors } \\
\text { - } & \text { No need } \mathrm{RF} \text { signal from reader to } \\
& \text { power the tag }\end{array}$ & $\begin{array}{l}\text { - Used internal power source (battery) } \\
\text { - Shorter life than semi-passive/semi- } \\
\text { active tag } \\
\text { - } \quad \text { Bigger tag size, expensive } \\
\text { - Increase maintenance and cost of } \\
\text { operation due to batteries replacement } \\
\text { especially when it involves a large } \\
\text { number of tags. } \\
\text { - Increase environmental pollution when } \\
\text { disposing of the old batteries }\end{array}$ \\
\hline
\end{tabular}


In the past few years, there are a number of multi-input energy harvesting systems that have been presented by researchers. A variety of circuit design architectures with various combinations of ambient sources and implementation of CMOS technology are introduced, all with the same goal which is to improve the harvester's performance with the maximum power conversion efficiency and minimal power losses.

A novel architecture of hybrid input energy harvester $(\mathrm{HIEH})$ system consisting of three sources of energy, which are radio frequency signal, thermal and vibration has been proposed in this paper. These sources are selected based on supply chain management purposes where they are readily available indoor energy sources. The ambient RF signal that is transmitted by the reader to activate the tag can be harvested by antenna and converted it to electrical energy. However due to limited and intermittent signal, RF source energy harvesting alone is not enough to extend the lifespan of semi-active RFID tag. Thus, energy from the thermal and vibration is required. Each of these sources can be generated from machine, human movement, and temperature differences.

In this work, the focus will be on the rectifiers and DC-DC converter circuits which will be designed in a standard $0.13 \mu \mathrm{m}$ CMOS technology. Ultra-low power design will be applied to ensure low power consumption in the system. Our contributions are by combining energy from different sources with efficient energy harvesting circuit design, it would be possible to eliminate the dependence on battery for power and continuously provide a stable power supply to the load. Hence, the overall semi-active RFID tag system reliability and functionality can be enhanced. Maintenance and cost of operation can also be reduced since the tag does not need any batteries replacement. Indirectly, this green energy solution can minimize the environmental pollution by reducing the disposal of old batteries and last but not least, making it possible to achieve a batteryless device.

This paper is organized as follows. Section 2 explains the basic RFID system. Overview of a single energy harvesting design is given in Section 3 followed by the hybrid energy harvesting design in Section 4. Next, the proposed block design and implementation process of HIEH architecture are discussed in Section 5 and Section 6 respectively. Finally, Section 7 concludes the paper.

\section{Basic RFID System}

RFID system uses radio frequency waves to locate, identify, track and sort objects, assets and equipment without direct contact or line of sight. The system consists of three components: a reader (transceiver), a tag (transponder) and a processing unit (a host computer) as shown in Fig. 1.

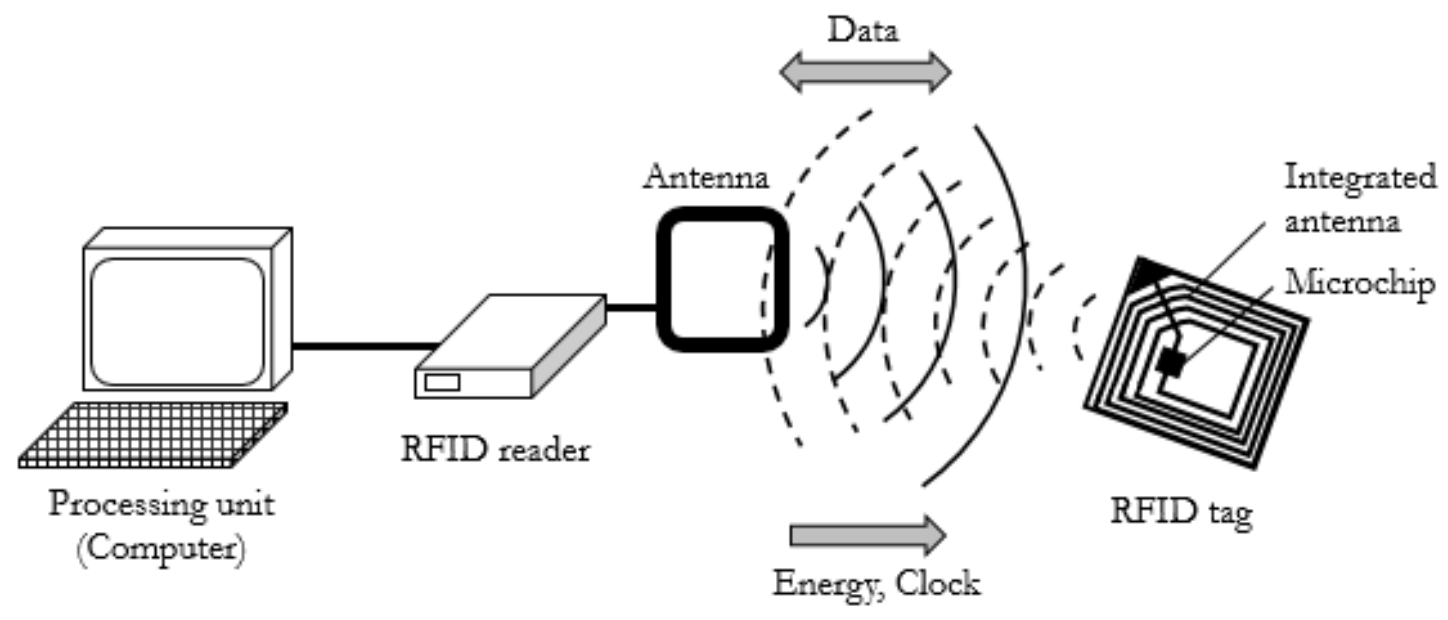

Fig. 1. RFID system.

The purpose of the RFID system is to transfer information between a tag and a reader to perform a specific application based on the data stored in the tag [4]. RFID tag can be categorized into three types: passive, semi-passive/semi-active and active. The most commonly used tags are passive tags. Passive tags do not have an internal battery and rely entirely on the reflected energy from the reader as their power source. They have a shorter read range, a small size, cheaper and do not require any maintenance $[5,6]$. On 
the contrary, active tags are powered by their own battery that is able to transmit their own information to a reader or other active tags. The internal battery is also used to power other electronic components and micro-sensors circuit such as temperature, pressure, humidity or vibration sensor which are integrated within the active tags. Similar to active tags, semi-active tags also have internal battery. However, they cannot communicate with other tags and only transmit their information once they receive a radio frequency (RF) signal from the reader [4].

\section{Overview of Energy Harvesting Design}

Energy harvesting is the process where energy is captured from the ambient sources such as temperature differences, light, vibrations and RF signals, converting it to electrical power or storing it for later use [7]. Due to its capabilities to supply a very small amount of power in the range of nanowatts to milliwatts, energy harvesting technology has attracted more attention to the researchers in finding a suitable input to supply ultra-low power devices such as in a modern wireless sensor network system, portable electronic devices, biomedical implants and RFID devices [8, 9]. With its typical micro-scale values, micro energy harvester can convert small amounts of energy from the ambient environmental sources into electrical power using electromagnetic waves, piezoelectric generators, thermoelectric generators (TEG), or photovoltaic devices $[10,11]$. The potential ambient energy available from various micro energy harvesting sources is shown in Table 2. Using energy harvesting techniques in the ultra-low power devices not only prolong the battery life and minimize cycle of exchanging or recharging the batteries [12] but also can indirectly extend the overall system lifetime, minimize the size and maintenance cost, and reduce waste produced by disposing batteries [13]. In this work, the focus will be on indoor energy sources which are thermal, vibration and RF.

Table 2. Performance of micro energy harvesting technologies [14].

\begin{tabular}{lcc}
\hline Energy source & Characteristics & Harvested power \\
\hline \multirow{2}{*}{ Light } & Indoor & $100 \mu \mathrm{W} / \mathrm{cm}^{2}$ \\
& Outdoor & $100 \mathrm{~mW} / \mathrm{cm}^{2}$ \\
\hline \multirow{2}{*}{ Thermal } & Human & $60 \mu \mathrm{W} / \mathrm{cm}^{2}$ \\
& Industrial & $10 \mathrm{~mW} / \mathrm{cm}^{2}$ \\
\hline \multirow{2}{*}{ Vibration } & Human & $4 \mu \mathrm{W} / \mathrm{cm}^{2}$ \\
& Industrial & $800 \mu \mathrm{W} / \mathrm{cm}^{2}$ \\
\hline \multirow{2}{*}{$\mathrm{RF}$} & $\mathrm{GSM}$ & $0.1 \mu \mathrm{W} / \mathrm{cm}^{2}$ \\
& $\mathrm{WiFi}$ & $0.001 \mu \mathrm{W} / \mathrm{cm}^{2}$ \\
\hline
\end{tabular}

\subsection{Radio Frequency}

Nowadays, RF energy harvesting has become one of the popular methods to supply power to a new generation of wireless communication and sensor devices. In this method, RF signal that are harvested by the antenna is converted to electrical energy (DC voltage). The signals have a frequency range between 30 $\mathrm{Hz}$ to $300 \mathrm{GHz}$ with a wavelength varying from $0.1 \mathrm{~cm}$ to $1000 \mathrm{~km}$ [15]. As in the semi-active RFID tag, the voltage generated at the tag terminal may be used either to transmit the data back to the reader or to recharge a battery to be supplied to the auxiliary circuit [16].

A basic block diagram of the RF energy harvesting system is shown in Fig. 2. The effectiveness of the system can be influenced by several factors such as antenna design, matching network circuit and RF-DC rectifier circuit design techniques. In order to maximize the efficiency of the harvester, the accuracy of the matching network circuit and RF-DC rectifier circuit have to be designed with regard to the ultra-low power RFID tag requirements [17]. For example, Le et al., [18] used a 36-stage floating-gate rectifier circuit designed in $0.25 \mu \mathrm{m}$ CMOS process to work with low input voltage as $50 \mathrm{mV}$ and low input power as 5.5 $\mu \mathrm{W}(-22.6 \mathrm{dBm})$. The circuit achieved a maximum efficiency of $60 \%$ at $906 \mathrm{MHz} \mathrm{RF}$ signal. Merz et al., [19] presented a system consisting of a quarter-wave monopole antenna, a T-match circuit, Greinacher multiplier circuit, a low-power comparator and a DC-DC converter. The complete system created a 
constant $1.8 \mathrm{~V} \mathrm{DC}$ output voltage at a frequency of $868 \mathrm{MHz}$ with an input power of $-6 \mathrm{dBm}$ which was ideal for powering wireless devices over long distances.

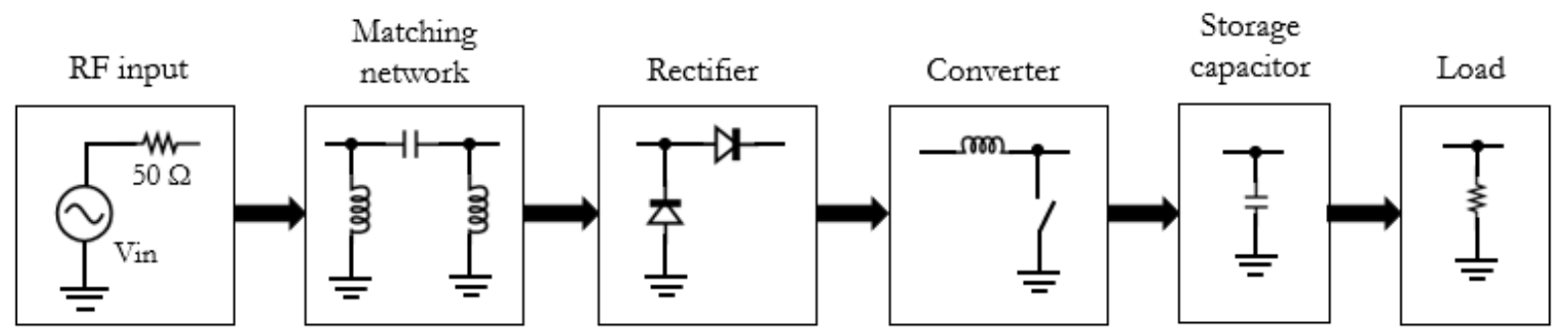

Fig. 2 Basic block diagram of RF energy harvesting.

Based on the literature review, it was noted that one of the most popular RF power harvesting methods for RFID tags is using the CMOS rectifier design [20]. Hashemi et al., [21] fabricated a full-wave CMOS rectifier in order to increase the output voltage and the power conversion efficiency (PCE), especially for small input voltage levels. Together with the bootstrapped capacitors technique, the effective threshold voltage can be reduced and the overall power efficiency improved by $11 \%$. Later, Kamalinejad et al., [22] presented a high-efficiency CMOS rectifier that attained 54\% PCE for the input voltage as low as $200 \mathrm{mV}$. This was achieved by boosting a gate-drive voltage using a chain of auxiliary floating rectifier cells at $950 \mathrm{MHz}$ RF signal. However, for applications that need intermittent communication, the sensitivity of the power harvester is more important than PCE as it determines the maximum range. A custom IC was fabricated by Oh et al., [20] in an IBM $130 \mathrm{~nm}$ CMOS process technology. At $915 \mathrm{MHz}$, a power harvester demonstrated the highest sensitivity of $-32 \mathrm{dBm}$ for $1 \mathrm{~V}$ output voltage. This was achieved by operating a CMOS rectifier in the subthreshold region, using low threshold voltage transistor and a matching network with a voltage boosting circuit.

Generally, for a small RF input power condition (e.g. RFID tag far from the reader), maximum PCE must be taken into the design considerations. For UHF RFID, a high-efficiency differential-drive CMOS rectifier circuit with an active threshold voltage $\left(\mathrm{V}_{\text {th }}\right)$ cancellation scheme was developed by Kotani et al., [23]. A rectifier circuit achieved $67.5 \%$ of PCE at $953 \mathrm{MHz},-12.5 \mathrm{dBm}$ RF input and $10 \mathrm{k} \Omega$ output load. On the other hand, a $900 \mathrm{MHz}$ system and an efficient power path structure with adaptive control was proposed by Hsieh and Chiang [24]. By adopting an open-loop adaptive control scheme and duty-cycled operation, the control circuit consumed low power and 35.7\% PCE was achieved at the input power of - 15 $\mathrm{dBm}$ when the output voltage reached $2 \mathrm{~V}$.

\subsection{Vibration}

Vibration energy harvesting can be divided into three types of energy transducers: piezoelectric, electrostatic and electromagnetic. However, among these transducers, piezoelectric has been widely studied due to its high power density, simple operating mechanism, no heat and easy to manufacture [3,25]. Not only that, piezoelectric materials such as lead zirconium titanate (PZT) are commonly used due to their ability to transform mechanical strain energy into electrical charge [26]. Figure 3 shows an electrical equivalent circuit and a basic block diagram of the piezoelectric energy harvesting system. It consists of a piezoelectric generator, rectifier, DC-DC converter, energy storage device and a load. To enhance the system performance, each block can be designed using different strategies. For example, Balpande et al., [27], in their design had successfully developed a power harvesting model using PZT as an alternative source for active RFID tags. The model applied Villard 6-stage voltage multiplier circuit using a dynamic threshold MOS technology and super capacitor as a storage device. Based on their simulation results, the proposed model can generate a maximum voltage and power of $7.36 \mathrm{~V}$ and $13.9 \mathrm{~mW}$ respectively, which were enough to power up the active tag that required only $7.5 \mu \mathrm{W}$ of power for $3-5 \mathrm{~s}$ of the interval. 

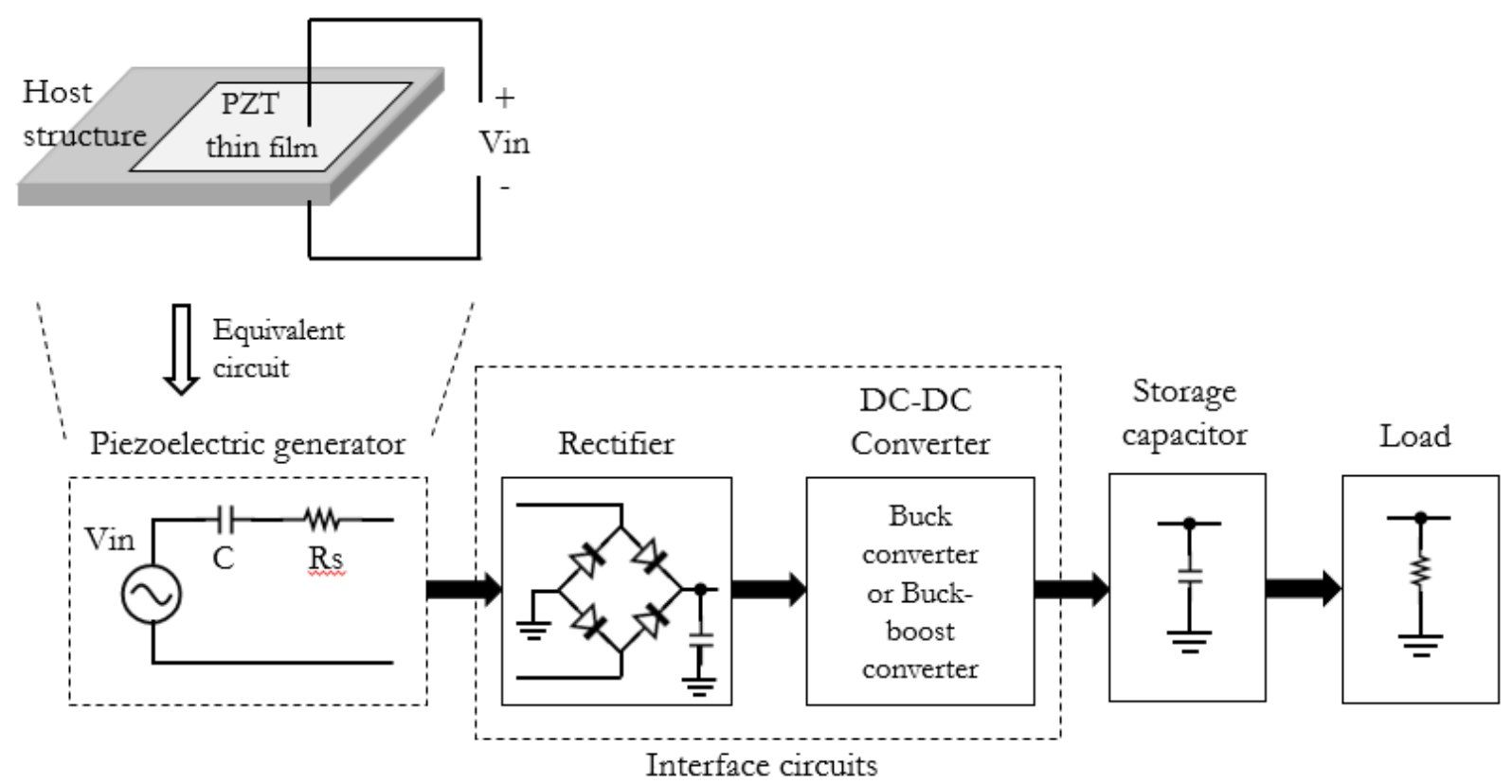

Fig. 3. Basic block diagram of piezoelectric energy harvesting.

A design of semi-active RFID tags with Piezoelectric Power Supply (PPS-RFID) for moving temperature sensing was presented by Chu et al., [3]. This PPS-RFID was used to record the temperature change information in a moving process. The single-layer PZT-4 piezoelectric vibrator, rectifier circuit, voltage regulator and energy storage circuit were used in the design. $0.242 \mu \mathrm{W}$ power of PPS and $5 \mathrm{~V}$ output voltage were achieved at $1 \mathrm{~Hz}$ vibration. According to Ramadass and Chandrakasan [26], interface circuits was one of the main drawbacks faced by existing piezoelectric harvesters. In their research, a biasflip rectifier circuit was introduced to enhance the power extracted from PZT. Compared to commonly used voltage doublers and full-bridge rectifiers, this bias-flip rectifier can extract power with four (4) times improvement. Chamanian et al., [28] considered a fully self-powered interface circuit to harvest energy from low power piezoelectric harvesters. Together with a novel peak detector and a synchronous switching technique, maximum energy can be extracted with the maximum power efficiency of $88 \%$ for an input power of $13.2 \mu \mathrm{W}$. In order to optimize the extracted power in a piezoelectric (PE) energy harvesting system, Do et al., [29] proposed a maximum power point tracking (MPPT) method and a DC-DC converter. The purpose was to overcome the low-efficiency problems faced by the conventional rectifiers design especially when the load resistance was outside the specific range. By implementing a full-bridge rectifier with an MPPT unit, a maximum of $51 \mu \mathrm{W}$ power can be extracted with the overall frequency of $64 \%$ regardless of the load variation.

\subsection{Thermal}

For thermal energy harvesting, thermoelectric generator (TEG) is used to convert heat energy into electrical energy when there are temperature differences by the Seebeck effect. An electrical potential will be generated in the circuit when there is a temperature gradient between two ends at two different temperatures (hot side and cold side) [30,31,32]. The advantages of the TEG are highly reliable, environmentally friendly, noiseless, compactness and lightweight [33, 34]. Saeki et al., [35] in their study proved that it was feasible to power up the RFID tag using thermal energy. Based on the evaluation results, they found out that the RFID tag performance using TEG was the same as the RFID tag driven by Lithium battery.

One problem of the TEG is its low generated power when dealing with a low-temperature gradient. As a solution, Chuan et al., [36] proposed a charge pump circuit as the power management approach in the TEG system. Compared with a boost converter, the output waveform of the charge pump was more stable and less ripple. Meanwhile, a thermoelectric energy harvesting interface circuit had been presented by Ramadass and Chandrakasan [30] to extract electrical energy from the human body heat. Without the aid of battery and the usage of mechanically assisted start-up circuit, the thermoelectric energy harvesting system 
was able to operate from input voltages as low as $35 \mathrm{mV}$ with $58 \%$ efficiency and reached $1.8 \mathrm{~V}$ output voltage. Lately, with the new development of thermoelectric materials and efficient modules, low efficiency of thermal harvesting is no longer a major obstacle to its extensive use where more than $10 \%$ efficiency has been reached [37]. Moreover, the TEG devices are also able to supply power in the range of $1 \mathrm{~W}$ up to several hundreds of Watts [33].

\section{Hybrid Energy Harvesting Design}

Hybrid energy harvesting is combining more than one ambient sources to generate electrical power out of a single system. By harvesting and combining energy from multiple sources, energy can flow continuously even though one or more sources are absent [34]. Hence, more power can be supplied and the overall system reliability and functionality can be enhanced $[11,38]$. The overall behaviour of the hybrid energy harvester is depending on the design of each component in the system. Due to the weakness, intermittence and inconsistency of single source energy harvesting, Tan and Panda [39] proposed a hybrid energy harvesting system using one power management circuit to not only extend the lifetime of the wireless sensor node but also to reduce the cost, form factor and power losses of the overall system. The designed and implemented ultra-low power management circuit with a fixed voltage reference MPPT consisted of a boost converter, an energy storage element and a regulating buck converter which produced an efficiency of $90 \%$ with the total power consumption of $135 \mu \mathrm{W}$. Subsequently, $\mathrm{Yu}$ et al., [40] used one power management circuit to decrease the power dissipation in their energy harvesting system. Unlike Tan and Panda [39], the architecture proposed by $\mathrm{Yu}$ et al., [40] consisted of an MPPT circuit, an impedance matching circuit, an energy storage, a bleed-off circuit and voltage regulator. The use of analog discrete components in the MPPT circuit had improved the overall harvester efficiency by $76.7 \%$.

Colomer-Farrarons et al., [41] developed a multiharvested self-powered system that focused on low voltage and low power applications such as RFID devices. The system was named as multiharvesting power chip which was robust against power failure. The main objective was to ensure that the system only worked with the energy harvested from the ambient sources and no longer depended on the battery. As shown in Fig. 4, the harvesting system was able to collect and manage energy from three ambient sources which were solar, vibration and RF. The maximum total power harvested is approximately $6.4 \mathrm{~mW}$ and the total power consumption was $160 \mu \mathrm{W}$. According to Nguyen et al., [42] a low amplitude, low frequency and low energy signal from the multi-energy sources can be harvested by using a novel hybrid CMOS rectifier. The proposed 6-stage hybrid rectifier circuit can generate a supply voltage of $1 \mathrm{~V}$ from a subthreshold amplitude of a $13.56 \mathrm{MHz}$ RF signal. Additionally, $40.3 \%$ of PCE was achieved compared to a traditional complimentary, cross-coupled rectifier circuit which was only $9.7 \%$. Meanwhile, in a feasibility study conducted by Mayordomo et al., [43] they stated that it was possible to combine low-power UHF RFID technology with energy harvesting to produce tags with sensing applications.

MSD1

(Multiple storage devices 1) MSD2

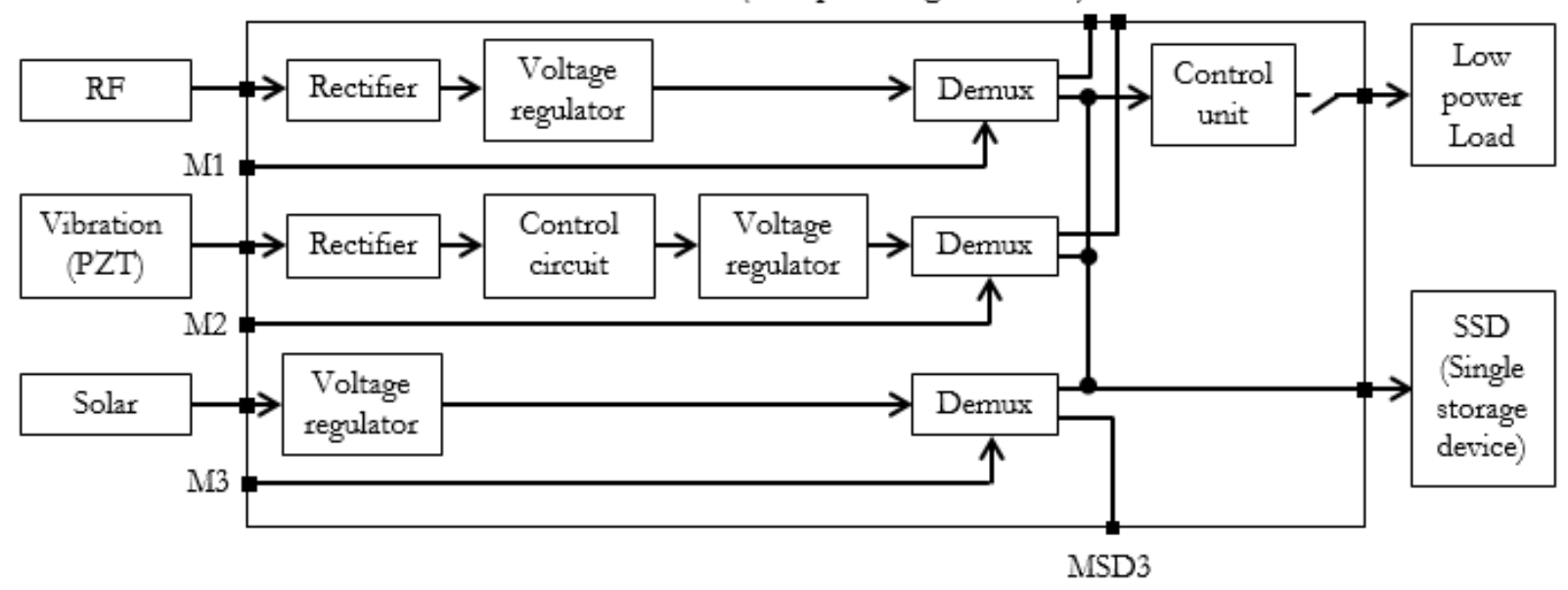

Fig. 4. Conventional architecture of the hybrid energy harvesting system with separate power management circuit [41]. 
Table 3. Circuit performance comparison of previously published hybrid energy harvesting design.

\begin{tabular}{|c|c|c|c|c|c|c|c|c|}
\hline Literature & Sources & Architecture & $\mathrm{V}_{\mathrm{IN}}(\mathrm{V})$ & $\begin{array}{l}\text { VoUT }_{\text {OU }} \\
(\mathrm{V})\end{array}$ & $\begin{array}{l}\text { Pout } \\
(\mathrm{mW})\end{array}$ & $\eta(\%)$ & $\begin{array}{l}\text { Technolog } \\
\text { y }\end{array}$ & Application \\
\hline $\begin{array}{l}\text { Colomer- } \\
\text { Farrarons et } \\
\text { al., [41] (2011) }\end{array}$ & $\begin{array}{l}\mathrm{PV}, \\
\mathrm{PZT}, \\
\mathrm{RF}\end{array}$ & $\begin{array}{l}\text { BG circuit, } \\
\text { LDO regulator, } \\
\text { bridge rectifier }\end{array}$ & $\begin{array}{l}1.89(\mathrm{PV}), \\
1.2(\mathrm{PZT}), \\
1(\mathrm{RF})\end{array}$ & $\begin{array}{l}1.2- \\
3.3\end{array}$ & 6.4 & $55-85$ & $\begin{array}{l}0.13 \mu \mathrm{m} \\
\text { ASIC }\end{array}$ & $\begin{array}{l}\text { Low-voltage } \\
\text { and low- } \\
\text { power loads } \\
\text { (e.g.: RFID) }\end{array}$ \\
\hline $\begin{array}{l}\text { Tan \& Panda } \\
\text { [39] (2011) }\end{array}$ & $\begin{array}{l}\text { PV, } \\
\text { Thermal }\end{array}$ & $\begin{array}{l}\text { DC-DC } \\
\text { converter, } \\
\text { PWM } \\
\text { generation, } \\
\text { micro- } \\
\text { controller, } \\
\text { energy storage }\end{array}$ & 3.6 & 5.5 & 0.621 & 90 & $\begin{array}{l}\text { Hardware } \\
\text { prototype }\end{array}$ & WSN \\
\hline $\begin{array}{l}\text { Bandyopadh- } \\
\text { yay \& } \\
\text { Chandrakasan } \\
\text { [11] (2012) }\end{array}$ & $\begin{array}{l}\text { TEG, } \\
\text { PV, } \\
\text { PZT }\end{array}$ & $\begin{array}{l}\text { Dual path } \\
\text { scheme, } \\
\text { inductor } \\
\text { sharing, ZCS }\end{array}$ & $\begin{array}{l}0.02-0.16 \\
(\mathrm{TEG}), \\
0.15-0.75 \\
(\mathrm{PV}), \\
1.5-5 \\
(\mathrm{PZT}) \\
\end{array}$ & 3.3 & $\begin{array}{l}1.3 \\
\text { (TEG), } \\
2.5 \text { (PV), } \\
0.2(\mathrm{PZT})\end{array}$ & $\begin{array}{l}58 \\
\text { (TEG), } \\
83(\mathrm{PV}), \\
79 \\
\text { (PZT) }\end{array}$ & $\begin{array}{l}0.35 \mu \mathrm{m} \\
\text { CMOS }\end{array}$ & WSN, DSP \\
\hline $\begin{array}{l}\text { Nguyen et al., } \\
\text { [42] (2014) }\end{array}$ & $\begin{array}{l}\text { RF, } \\
\text { PZT }\end{array}$ & $\begin{array}{l}\text { Hybrid } \\
\text { rectifier, CCCR } \\
\text { chain, matching } \\
\text { network, bias } \\
\text { generator }\end{array}$ & $\begin{array}{l}0.3 \text { (RF), } \\
2.0 \text { (PZT) }\end{array}$ & 1 & $\begin{array}{l}\text { Not } \\
\text { stated }\end{array}$ & 40.3 & $\begin{array}{l}0.09 \mu \mathrm{m} \\
\mathrm{CMOS}\end{array}$ & RFID sensor \\
\hline
\end{tabular}

\begin{tabular}{|c|c|c|c|c|c|c|c|c|}
\hline $\begin{array}{l}\text { Lim et al., [38] } \\
\text { (2014) }\end{array}$ & $\begin{array}{l}\text { TEG, } \\
\text { PV, } \\
\text { PZT }\end{array}$ & $\begin{array}{l}\text { DC-DC boost } \\
\text { converter with } \\
\text { MPPT, VCCS }\end{array}$ & $0.18-0.907$ & $\begin{array}{l}0.310 \\
-27.9\end{array}$ & $\begin{array}{l}0.014- \\
0.187\end{array}$ & $\begin{array}{l}\text { Not } \\
\text { stated }\end{array}$ & Not stated & $\begin{array}{l}\text { WSN, cardiac } \\
\text { pace makers, } \\
\text { Quartz } \\
\text { watches and } \\
\text { hearing aids }\end{array}$ \\
\hline $\begin{array}{l}\text { Chou et al. } \\
\text { [44] (2014) }\end{array}$ & $\begin{array}{l}\text { PV, } \\
\text { PZT }\end{array}$ & $\begin{array}{l}\text { Full-wave } \\
\text { rectification, } \\
\text { PFM boost } \\
\text { switching } \\
\text { regulator }\end{array}$ & $0.2-1.7$ & $\begin{array}{l}1.8- \\
3.7\end{array}$ & 2.4 & 73 & $\begin{array}{l}0.35 \mu \mathrm{m} \\
\text { CMOS }\end{array}$ & $\begin{array}{l}\text { Biomedical } \\
\text { sensing } \\
\text { system }\end{array}$ \\
\hline $\begin{array}{l}\text { Dini et al., [45] } \\
(2015)\end{array}$ & $\begin{array}{l}\text { PZT, } \\
\text { TEG, } \\
\text { PV, } \\
\text { RF }\end{array}$ & $\begin{array}{l}\text { Buck-boost } \\
\text { converter, } \\
\text { LDO regulator, } \\
\text { UVLO circuit, } \\
\text { bias generator, } \\
\text { nano power } \\
\text { comparators, } \\
\text { NVC }\end{array}$ & $\begin{array}{l}0.7-5 \\
(\mathrm{PZT}) \\
1-5(\mathrm{HV}) \\
0.1-1(\mathrm{LV})\end{array}$ & 5 & 2.124 & 89.6 & $\begin{array}{l}0.32 \mu \mathrm{m} \\
\mathrm{BCD}\end{array}$ & WSN \\
\hline $\begin{array}{l}\text { Vanhecke et } \\
\text { al. [46] (2015) }\end{array}$ & $\begin{array}{l}\text { TEG, } \\
\text { PZT }\end{array}$ & $\begin{array}{l}\text { Voltage } \\
\text { doubler, LDO, } \\
\text { PTAT, BGR }\end{array}$ & 3 & 2.4 & $\begin{array}{l}\text { Not } \\
\text { stated }\end{array}$ & 66 & $\begin{array}{l}0.35 \mu \mathrm{m} \\
\text { CMOS }\end{array}$ & $\begin{array}{l}\text { Aeronautics } \\
\text { applications }\end{array}$ \\
\hline $\begin{array}{l}\text { This work } \\
(2016)\end{array}$ & $\begin{array}{l}\text { RF, } \\
\text { PZT, } \\
\text { TEG }\end{array}$ & $\begin{array}{l}\text { Rectifier, } \\
\text { matching } \\
\text { network, DC- } \\
\text { DC converter, } \\
\text { control loop, } \\
\text { ACC, voltage } \\
\text { regulator }\end{array}$ & $0.1-5$ & 3.3 & 6.5 & 90 & $\begin{array}{l}0.13 \mu \mathrm{m} \\
\text { CMOS }\end{array}$ & $\begin{array}{l}\text { RFID semi- } \\
\text { active tag }\end{array}$ \\
\hline
\end{tabular}


Table 3 shows the circuit performance comparison of previously published hybrid energy harvesting design. From this literature, Bandyopadhyay and Chandrakasan [11] and Dini et al., [45] had reported on fabricated die micrograph in their designs. In Bandyopadhyay and Chandrakasan work, they presented a dual-path architecture that combined three input sources (solar, thermal and vibration) which closely resembled to the proposed HIEH architecture, where the only difference was between solar and RF input. Fig. 5 shows a chip micrograph designed by them. The circuit was implemented in a $0.35 \mu \mathrm{m}$ CMOS technology with a chip size of $5 \mathrm{~mm} \times 5 \mathrm{~mm}$. With inductor sharing, $83 \%, 58 \%$ and $79 \%$ of peak efficiencies were achieved for photovoltaic, thermoelectric and piezoelectric dual-path architecture respectively.

Based on the literature review, it can be noticed that energy harvesting circuits design that were interfacing between the harvesters and power converter played an important role in the development of efficient and effective energy harvesting system. Maximum power can be harvested if the input impedance of the DC-DC converter circuits was designed to be equal to the harvester's internal impedance [11]. In certain architectures, an additional interface circuit is needed to match the characteristics of the harvester and the power converter [45]. Thus in this research, our focus will be on the rectifiers and DC-DC converter circuits design. In attempting to achieve maximum PCE with minimal power losses, the correct circuit implementations and the selection of the good topology of each harvester will be emphasized.

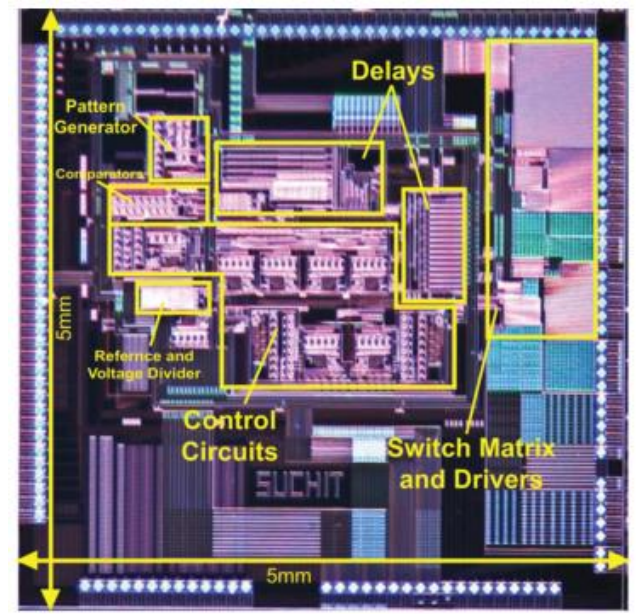

Fig. 5. Die micrograph of the chip test [11].

\section{Proposed HIEH Block Design}

The block diagram of the proposed architecture of HIEH system is illustrated in Fig. 6. The system is designed to harvest energy from three input sources which are PZT, TEG and RF signal. It consists of a matching network, rectifiers (AC-DC and RF-DC), a self-start-up circuit, a control loop, an adaptive control circuit (ACC) block, DC-DC converter with MPPT, an energy storage unit and a voltage regulator. All of these blocks will be integrated and implemented into a chip to supply the required ultra-low power to the semi-active UHF RFID tag as well as a low power microcontroller and sensors.

Since PZT element is an AC voltage source, an AC-DC rectifier is required before interfacing with the DC-DC converter. The purpose is to convert the alternating current into direct current for usage in the device. In the case of RF energy harvesting, RF-DC rectifier is designed to convert the ambient RF energy received by the antenna to a DC supply voltage [47]. Unlike PZT, a matching network is necessary before the rectifier circuit. The matching network is used to increase the power acquired from the antenna so that maximum power can be delivered to the RF-DC rectifier circuit [13], [19]. 


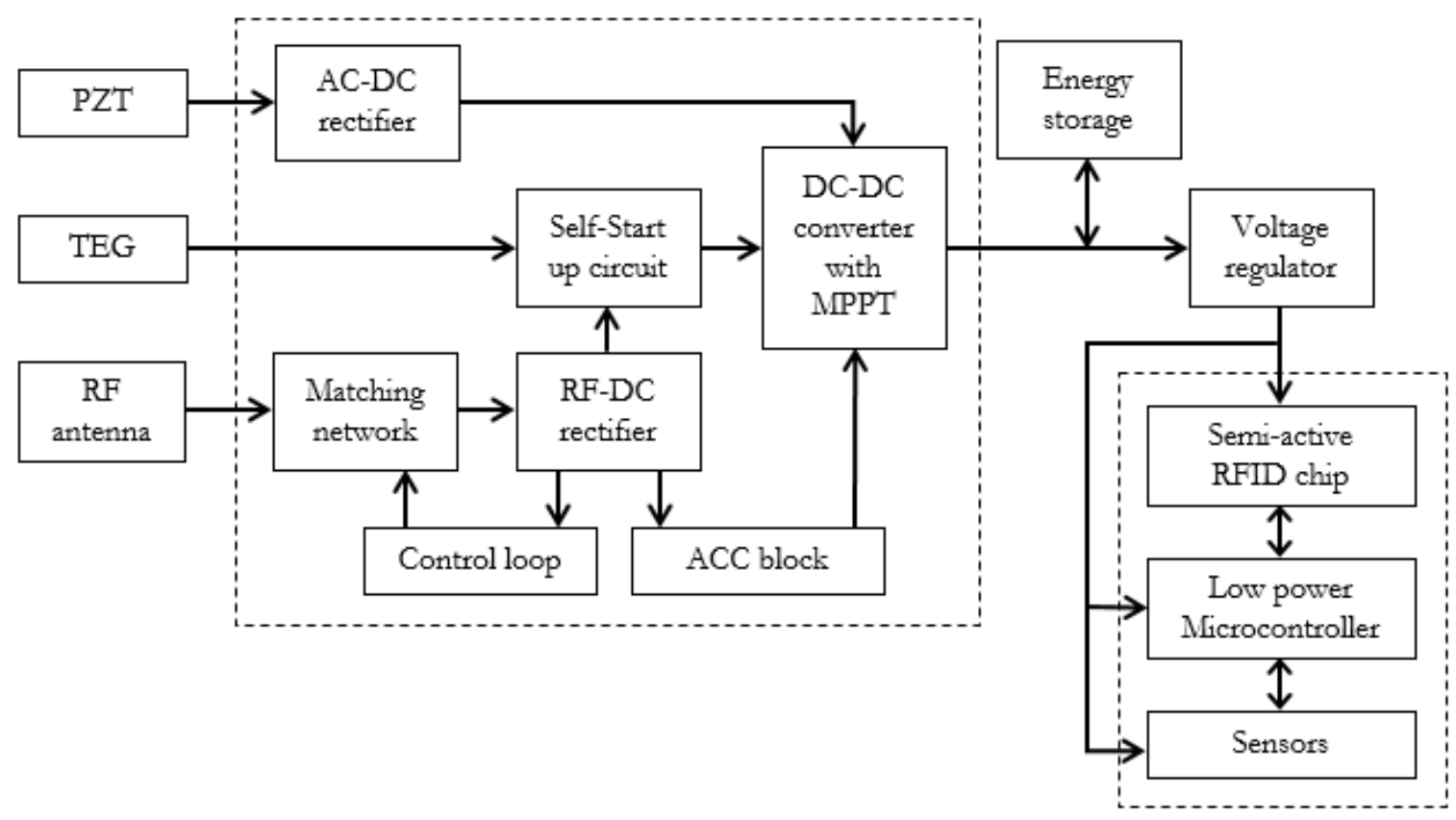

Fig. 6. Block diagram of the proposed architecture of HIEH for semi-active RFID tag.

Until now, there are several kinds of circuit topology have been introduced by researchers to be applied to the rectifier in RFIDs. Some of them are full-wave CMOS rectifier [21] and a high-efficiency differentialdrive CMOS rectifier [22]. The advantage of these circuit is that they do not require a complex circuit design [21], well established and have a good efficiency [22]. Indeed, the selection of a suitable diode is important in designing a low-power rectifier circuit. Its parameters and characteristics such as the breakdown voltage, zero-bias junction capacitance, forward bias current, switching speed and cut-off voltage can affect the performance and PCE of the energy harvesting circuit [48]. Since the proposed HIEH system is operating at UHF band $(860-960 \mathrm{MHz})$, diodes with very fast switching speed, low forward voltage drop and high detection sensitivity at UHF frequencies are required. For these reasons, Schottky diodes are considered to be an ideal choice. However, their implementation cost is high and it is not compatible with the standard CMOS processes. As an alternative, Schottky diode can be replaced with a diode-connected MOSFET [49]. Even though the PCE for a rectifier will be worse than that of the Schottky diode, by applying threshold voltage cancellation techniques, the PCE can be improved tremendously [23].

As the high-Q loop antenna is very sensitive to impedance variation at the antenna-rectifier interface, a control loop is added in the proposed architecture. The purpose is to compensate the input impedance so that a resonance can be achieved between the rectifier and the loop antenna for any given frequency and input impedance. Thereby, the RF energy harvester robustness can be improved with the advantage of the passive voltage boost obtained from the high-Q resonator [50, 51].

Meanwhile, a self-startup circuit is added to ensure the energy extraction process starts charging once the stored energy is low. After startup, DC voltage of the harvested energy will pass to a DC-DC converter to convert the input voltage to another voltage level. In this research, DC-DC converter with voltage reference MPPT control will be implemented so that the maximum power extraction can be derived from the HIEH system. Next, an adaptive control circuit is added to maintain close-to-optimal PCE of the rectifier until the output voltage reaches the required value. The process will be done by adjusting the internal impedances between blocks and the switching timing of the entire power path dynamically to improve the output power throughout the charging process [52]. Then, energy storage unit is required in this system, especially when the amount of energy harvested is limited and intermittent. The purpose is to store harvested energy until it is enough to supply power required by the loads. Finally, the voltage regulator is utilized so that a stable supply voltage can be generated for the loads: semi-active RFID chip, microcontroller and sensors.

In the proposed architecture of HIEH, temperature, vibration and voltage sensors will be added to the system for military assets security purposes. Since most of the military assets are dangerous and sensitive 
such as weapons and ammunition, it is important to keep them safe from being stolen or moved out by unauthorized personnel, especially terrorists. These sensors will alert authorities if they sense small changes in vibration, temperature or voltage that occur on the weapons and ammunition. Meanwhile, the microcontroller is used to control both the RFID tag and the sensors [43]. In this architecture, a low power microcontroller is used to ensure low power consumption in the system.

\section{Implementation Process of HIEH Architecture}

Figure 7 shows the design flow chart of the proposed HIEH system. The design will start with a review of the research studies that have been previously published for a single and hybrid input energy harvesting system. The review is compared based on the types of harvester, design architecture, fabrication process and measurement results. From the literature, objectives and scopes of the research will be set and new HIEH architecture will be proposed. Then, the new architecture will be designed, modelled and simulated using PSpice software. At this stage, the performance of the proposed architecture such as the input and output voltages, input and output power, PCE, etc. will be measured. Once the best results are achieved, the design will proceed to the next step which is behavioral modelling of HIEH in Verilog using Mentor Graphics. If there are no errors in the design, the source code will be written using Verilog followed by a simulation work using ModelSim from Mentor Graphics. Any errors will loop back to the behavioral modelling stage.

Next, the Precision Synthesis tool will be used to perform logic synthesis. In synthesis, Verilog code will be translated into an Electronic Design Interface Format (EDIF) netlist file to enable a timing and gate level simulation in FormalPro. If there are any errors in the timing and gate level simulation, the synthesis process will be repeated before being downloaded to FPGA (field-programmable gate array) for real-time verification. Once the FPGA implementation is successful, the developed HIEH will be designed and implemented on $0.13 \mu \mathrm{m}$ CMOS process technology to obtain its final layout. Then, circuit verification will be done using CALIBRE tool. During this step, the layout will be analyzed and compared versus the schematic to ensure design integrity. The design will also be analyzed in case any electrical failures and multiple validations will be consumed by a downstream simulator to determine whether the design meets the electrical specifications such as design rule check, layout versus schematic, parasitic extraction, power issues, etc. Finally, after IC layout physical verification is completed, the data will be translated into GDSII file format through the tapeout process to possibly be fabricated for RFID device implementation and others.

\section{Conclusions}

In this paper, the drawbacks of the semi-active RFID tag and the previously proposed solutions have been reviewed. Based on the findings, an ultra-low power HIEH system with three input ambient sources from RF, TEG and PZT has been proposed as a solution. The main objective is to solve the semi-active UHF RFID tag limited lifespan issues due to the need for batteries to power their circuitries and to achieve maximum PCE with minimal power losses obtain from the HIEH system. To achieve the target, the proposed architecture will use rectifiers, matching network, a self-start-up circuit, DC-DC boost converter with MPPT, a control loop, an adaptive control circuit, energy storage and a voltage regulator. Each designed topology will be evaluated and characterized to get a maximum PCE. PSpice software and Verilog based on Mentor Graphics will be used for design simulation and code writing respectively. Then, the circuits design will be downloaded to the FPGA board for verification and the final layout will be implemented in a standard $0.13 \mu \mathrm{m}$ CMOS process. The simulation result from this ultra-low power HIEH architecture is expected to deliver a total of $3.3 \mathrm{~V}$ of output voltage from low input ambient sources which is enough to recharge the battery and activate the semi-active RFID tag. Moreover, $6.5 \mathrm{~mW}$ of output power and 90\% efficiency are expected when three input sources are simultaneously harvested.

\section{Acknowledgement}

The authors gratefully acknowledge the support provided by UKM internal grant (GUP-2015-021) and grant from ministry of education (FRGS/2/2014/TK03/UKM/02/1) for this research. 


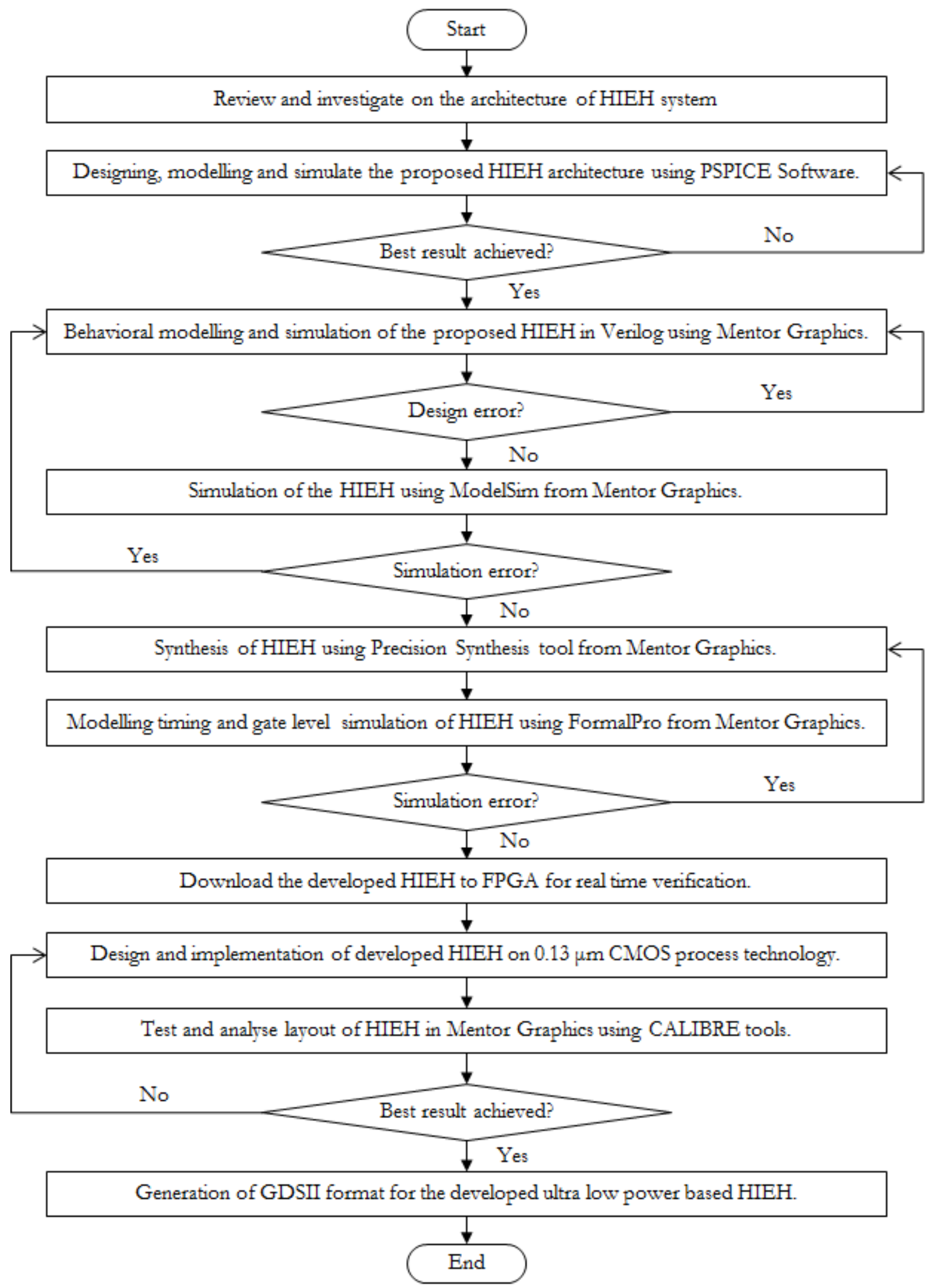

Fig. 7. Design flow chart of HIEH architecture. 


\section{References}

[1] T. Mehta, "Convert UHF RFID tag from passive to semi-passive tag using external power sources," University of Texas At Arlington, 2010.

[2] Q. Xiao, C. Boulet, and T. Gibbons, "RFID security issues in military supply chains," in Second International Conference on Availability, Reliability and Security (ARES'07), 2007, pp. 599-605.

[3] H. Chu, G. Wu, J. Chen, and Y. Zhao, "Study and simulation of semi-active RFID tags using piezoelectric power supply for mobile process temperature sensing," in International Conference on Cyber Technology in Automation, Control and Intelligent Systems, 2011, no. 1, pp. 38-42.

[4] Q. Xiao, T. Gibbons, and H. Lebrun, "RFID technology, security vulnerabilities and countermeasures," in Supply Chain, The Way to Flat Organisation. Publisher-Intech, 2009, pp. 357-382.

[5] Y. Duroc and D. Kaddour, "RFID potential impacts and future evolution for green projects," Energy Procedia, vol. 18, pp. 91-98, 2012.

[6] J. Sampe, "Reliable and higher throughput anti-collision technique for RFID UHF tag," World Applied Sciences Journal, vol. 20, no. 3, pp. 445-449, 2012.

[7] A. Castagnetti, A. Pegatoquet, C. Belleudy, and M. Auguin, "A framework for modeling and simulating energy harvesting WSN nodes with efficient power management policies," EURASIP Journal on Embedded Systems, vol. 8, pp. 1-20, 2012.

[8] A. M. A. Hadi, S. N. M. Tawil, T. N. T. Mohamad, and M. Syaripuddin, "Energy harvesting from road by pyroelectric effect," ARPN Journal of Engineering and Applied Sciences, vol. 10, no. 20, pp. 9884-9890, 2015.

[9] H. Dai, Y. Lu, M. Law, S. Sin, and R. P. Martins, "A review and design of the on-chip rectifiers for RF energy harvesting," in IEEE International Wireless Symposium (IWS), 2015, pp. 1-4.

[10] D. M. M. Rahaman, M. S. Islam, J. Sampe, and S. H. M. Ali, "An architecture of ULP energy harvesting power conditioning circuit using piezoelectric transducer for wireless sensor network: A review," Asian Journal of Scientific Research, vol. 8, no. 1, pp. 1-13, 2015.

[11] S. Bandyopadhyay and A. P. Chandrakasan, "Platform architecture for solar, thermal and vibration energy combining with MPPT and single inductor," IEEE Journal of Solid-State Circuits, vol. 47, no. 9, pp. 2199-2215, 2012.

[12] M. A. Albrni, J. Sampe, M. S. Islam, and B. Y. Majlis, "Ultra low power energy harvester using hybrid input for wireless communication devices-A review," Journal of Theoretical and Applied Information Technology, vol. 86, no. 3, pp. 365-376, 2016.

[13] B. Beikzadeh, "Design and implementation of a micro scale radio frequency energy harvester," EURECA, pp. 75-76, 2013.

[14] A. Nechibvute, A. Chawanda, and P. Luhanga, "Piezoelectric energy harvesting devices: An alternative energy source for wireless sensors," Smart Materials Research, vol. 2012, pp. 1-13, 2012.

[15] N. G. Kurahatti, "Novel method for design and implementation of low power FPGA based RFID system," in IEEE International Conference on Electrical, Computer and Communication Technologies (ICECCT), 2015, pp. 1-6.

[16] M. A. Khan, M. Sharma, and B. Prabhu R, "A survey of RFID tags," International Journal of Recent Trends in Engineering, vol. 1, no. 4, pp. 4-7, 2009.

[17] X. Lu, P. Wang, D. Niyato, D. Kim, and Z. Han, "Wireless networks with RF energy harvesting: A contemporary survey," IEEE Communications Surveys and Tutorials, vol. 17, no. 2, pp. 1-33, 2015.

[18] T. Le, K. Mayaram, and T. Fiez, "Efficient far-field radio frequency energy harvesting for passively powered sensor networks," IEEE Journal of Solid-State Circuits, vol. 43, no. 5, pp. 1287-1302, 2008.

[19] C. Merz, G. Kupris, and M. Niedernhuber, "Design and optimization of a radio frequency energy harvesting system for energizing low power devices," in International Conference on Applied Electronics (AE), 2014, pp. 209-212.

[20] S. Oh and D. D. Wentzloff, "A -32dBm sensitivity RF power harvester in 130nm CMOS," in IEEE Radio Frequency Integrated Circuits Symposium (RFIC), 2012, pp. 483-486.

[21] S. S. Hashemi, M. Sawan, and Y. Savaria, "A high-efficiency low-voltage CMOS rectifier for harvesting energy in implantable devices," IEEE Transactions on Biomedical Circuits and Systems, vol. 6, no. 4, pp. 326-335, 2012.

[22] P. Kamalinejad, K. Keikhosravy, S. Mirabbasi, and V. C. M. Leung, "An efficiency enhancement technique for CMOS rectifiers with low start-up voltage for UHF RFID tags," in International Green 
Computing Conference (IGCC), 2013, pp. 1-6.

[23] K. Kotani, A. Sasaki, and T. Ito, "High-efficiency differential-drive CMOS rectifier for UHF RFIDs," IEEE Journal of Solid-State Circuits, vol. 44, no. 11, pp. 3011-3018, 2009.

[24] P.-H. Hsieh and T. Chiang, "An RF energy harvester with 35.7\% PCE at P IN of -15 dBm," in Symposium on. IEEE VLSI Circuits (VLSIC), 2013, pp. 224-225.

[25] J. Bing, C. Kun, C. Lijuan, C. Hong, Z. Huaqing, and W. Qiang, "Low-power design of a selfpowered piezoelectric energy harvesting system," in Proceedings of the 33rd Chinese Control Conference, 2014, pp. 6937-6940.

[26] Y. K. Ramadass and A. P. Chandrakasan, "An efficient piezoelectric energy harvesting interface circuit using a bias-flip rectifier and shared inductor," IEEE Journal of Solid-State Circuits, vol. 45, no. 1, pp. 189-204, 2010.

[27] S. S. Balpande, S. B. Lande, U. Akare, and L. Thakre, "Modeling of cantilever based power harvester as an innovative power source for RFID Tag," in Second International Conference on Emerging Trends in Engineering and Technology, ICETET-09, 2009, pp. 13 - 18.

[28] S. Chamanian, Ö. Zorlu, H. Külah, and A. Muhtaroğlu, "An adaptive piezoelectric energy harvesting interface circuit with a novel peak detector," in International Conference on Energy Aware Computing Systems \& Applications (ICEAC), 2015, pp. 1-4.

[29] X.-D. Do, S.-K. Han, and S.-G. Lee, "Optimization of piezoelectric energy harvesting systems by using a MPPT method," in IEEE Fifth International Conference on Communications and Electronics (ICCE), 2014, pp. 309-312.

[30] Y. K. Ramadass and A. P. Chandrakasan, "A battery-less thermoelectric energy harvesting interface circuit with $35 \mathrm{mV}$ startup voltage," IEEE Journal of Solid-State Circuits, vol. 46, no. 1, pp. 333-341, 2011.

[31] M. I. A. Jalil and J. Sampe, "Experimental investigation of thermoelectric generator modules with different technique of cooling system," American Journal of Engineering and Applied Sciences, vol. 6, no. 1, pp. 1-7, 2013.

[32] F. Jfri, S. N. M. Tawil, M. Syaripuddin, T. N. T. Mohamad, and A. Miskon, "Employment of waste heat for thermoelectric-based energy harvesting," ARPN Journal of Engineering and Applied Sciences, vol. 10, no. 20, pp. 9896-9901, 2015.

[33] A. Paraskevas and E. Koutroulis, "A simple maximum power point tracker for thermoelectric generators," Energy Conversion and Management, vol. 108, pp. 355-365, 2016.

[34] N. A. A. Semsudin, J. Sampe, M. S. Islam, A. R. M. Zain, and D. D. Berhanuddin, "Architecture of ultra-low-power micro Energy harvester using hybrid input for biomedical devices," in IEEE Regional Symposium on Micro and Nanoelectronics (RSM), 2015, pp. 1-4.

[35] R. Saeki, J. Yoshino, and M. Inoue, "Active RFID tag drive using thermoelectric conversion element," in IEEE 2nd Global Conference on Consumer Electronics (GCCE), 2013, pp. 269-270.

[36] L. C. Chuan, H. Wahid, and L. P. Ling, "A charge pump-based power conditioning circuit for low powered thermoelectric generator (TEG)," in 10th Asian Control Conference (ASCC), 2015, pp. 1-6.

[37] F. Karim and S. Zeadally, "Energy harvesting in wireless sensor networks: A comprehensive review," Renewable and Sustainable Energy Reviews, vol. 55, pp. 1041-1054, 2016.

[38] M. S. M. Lim, S. H. M. Ali, S. Jahariah, and M. S. Islam, "Modelling of hybrid energy harvester with DC-DC boost converter using arbitary input sources for ultra-low-power micro-devices," in IEEE International Conference on Semiconductor Electronics (ICSE), 2014, pp. 28-31.

[39] Y. K. Tan and S. K. Panda, "Energy harvesting from hybrid indoor ambient light and thermal energy sources for enhanced performance of wireless sensor nodes," IEEE Transactions on Industrial Electronics, vol. 58, no. 9, pp. 4424-4435, 2011.

[40] H. Yu, Q. Yue, J. Zhou, and W. Wang, "A hybrid indoor ambient light and vibration energy harvester for wireless sensor nodes," Sensors, vol. 14, no. 5, pp. 8740-8755, 2014.

[41] J. Colomer-Farrarons, P. Miribel-Catala, A. Saiz-Vela, and J. Samitier, "A multiharvested selfpowered system in a low-voltage low-power technology," IEEE Transactions on Industrial Electronics, vol. 58, no. 9, pp. 4250-4263, 2011.

[42] T. T. Nguyen, T. Feng, P. Häflinger, and S. Chakrabartty, "Hybrid CMOS rectifier based on synergistic RF-piezoelectric energy scavenging," IEEE Transactions on Circuits and Systems - I: Regular Papers, vol. 61, no. 12, pp. 3330-3338, 2014.

[43] I. Mayordomo, L. Mateu, M. Roth, D. Sobirai, K. Alexander, P. Spies, and M. Ulli, "An evaluation of energy harvesting for smart UHF RFID tags," in European Conference on Smart Objects, System and 
Technologies (Smart Sys Tech), 2014, pp. 1-8.

[44] Y. Y. Chou, C. C. Wu, Y. H. Chen, Y. C. Huang, Y. C. Chiu, L. J. Tsai, W. C. Hsieh, W. C. Li, Y. J. Huang, and S. S. Lu, "Multi-input energy harvesting interface for low- power biomedical sensing system," in International Symposium on Next-Generation Electronics (ISNE), 2014, pp. 1-2.

[45] M. Dini, A. Romani, M. Filippi, V. Bottarel, G. Ricotti, and M. Tartagni, "A nanocurrent power management IC for multiple heterogeneous energy harvesting sources," IEEE Transactions on Power Electronics, vol. 30, no. 10, pp. 5665-5680, 2015.

[46] C. Vanhecke, L. Assou, A. Wang, P. Durand-Estebe, F. Caignet, J.-M. Dilhac, M. Bafleur, M. Bafleur, C. Vanhecke, L. Assou, A. Wang, P. Durand-est, F. Caignet, C. Vanhecke, L. Assouère, A. Wang, P. Durand-estèbe, and F. Caignet, "Multisource and battery-free energy harvesting architecture for aeronautics applications," IEEE Transactions on Power Electronics, vol. 30, no. 6, pp. 3215-3227, 2015.

[47] E. Khansalee, K. Nuanyai, and Y. Zhao, "A Dual-Band Rectifier for RF Energy Harvesting," Engineering Journal, vol. 19, no. 5, pp. 189-197, 2015.

[48] B. A. Mouris and I. A. Eshrah, "Highly efficient UHF energy harvesting module for RFID applications," in IEEE Antennas and Propagation Society International Symposium (APSURSI), 2014, pp. 1302-1303.

[49] F. F. Zulkifli, J. Sampe, M. S. Islam, M. A. Mohamed, and S. A. Wahab, "Optimization of RF- DC converter in micro energy harvester using voltage boosting network and bulk modulation technique for biomedical devices," in IEEE Regional Symposium on Micro and Nanoelectronics (RSM), 2015, pp. 1-4.

[50] M. Stoopman, S. Keyrouz, H. J. Visser, K. Philips, and W. A. Serdijn, "Co-design of a CMOS rectifier and small loop antenna for highly sensitive RF energy harvesters," IEEE Journal of SolidState Circuits, vol. 49, no. 3, pp. 622-634, 2014.

[51] F. F. Zulkifli, J. Sampe, M. S. Islam, and M. A. Mohamed, "Architecture of ultra low power micro energy harvester using RF signal for health monitoring system: A review," American Journal of Applied Sciences, vol. 12, no. 5, pp. 335-344, 2015.

[52] P.-H. Hsieh, C.-H. Chou, and T. Chiang, "An RF energy harvester with 44.1\% PCE at input available power of $-12 \mathrm{dBm}$," IEEE Transactions on Circuits and Systems - I: Regular Papers, vol. 62, no. 6, pp. 1528-1537, 2015. 